\title{
The hydrodynamic foundation for salmon lice dispersion modeling along the Norwegian coast
}

\author{
Lars Asplin $^{1}$ (D) $\cdot$ Jon Albretsen ${ }^{1} \cdot$ Ingrid Askeland Johnsen ${ }^{1} \cdot$ Anne Dagrun Sandvik ${ }^{1}$
}

Received: 20 December 2019 / Accepted: 21 April 2020 / Published online: 6 May 2020

(C) The Author(s) 2020

\begin{abstract}
Norway has complicated dynamics in the coastal ocean and in the fjords. In this area is also the largest salmon aquaculture industry in the world. The salmon industry is valuable for Norwegian economy worth more than 60 billion NOK. Thus, it is important to know the physical oceanography along the coast, even variability on short temporal and spatial scales $(\mathrm{h} / \mathrm{km})$, to be able to quantify environmental effects of the aquaculture industry. This is the motivation behind the implementation of a current model covering the whole coast of Norway with a relatively high spatial grid size of $800 \mathrm{~m}$. The NorKyst 800 is an implementation of the ROMS current model with an elaborated system of forcing and boundary conditions. This model has an important role for Norwegian authorities in various management purposes. We show that the NorKyst 800 results are realistic and typically deviating at most by $1{ }^{\circ} \mathrm{C}$ and one unit in salinity from observations. The currents in the upper $10-20 \mathrm{~m}$ of the water column vary in a similar way as observed current and the agreement is good. The usefulness of a tool like the NorKyst800 is illustrated by an example of dispersion of salmon lice which is the biggest problem the salmon industry presently is facing. Detailed information, as can be provided by NorKyst800, is needed to fully understand and quantify environmental effects of the aquaculture industry. Similar modeling systems describing the planktonic salmon lice concentration operationally could be beneficial also in other salmon-producing countries like Scotland, Canada, or Chile. The major requirement will be access to updated number of fish and female lice per fish on a weekly time scale.
\end{abstract}

Keywords High-Resolution Ocean modeling $\cdot$ Salmon lice dispersion $\cdot$ Model validation $\cdot$ Fjords

\section{Introduction}

The coast of Norway is about $2000 \mathrm{~km}$ long from south to north. The average depth of the shelf along the coast is $300 \mathrm{~m}$, and further offshore is the much deeper Norwegian sea. Stretching in from the coast are numerous fjords, some with deep basins that ranges down to $600-1300 \mathrm{~m}$. Altogether, both the bathymetry and topography of the Norwegian coastal areas are complicated.

This article is part of the Topical Collection on the 11th International Workshop on Modeling the Ocean (IWMO), Wuxi, China, 17-20 June 2019

Responsible Editor: Shanlin Wang

Lars Asplin

lars.asplin@imr.no

1 Institute of Marine Research, PO Box 1870 Nordnes, 5817 Bergen, Norway
Along the Norwegian coast flows the Norwegian Coastal Current (NCC). The NCC is primarily fed and mostly driven by freshwater from the Baltic and a large number of Norwegian rivers (Sætre 2007). Hence, the water masses are stratified from this variable but continuous supply of freshwater. The transport of the NCC is around 1-2 Sv, and the current is wedge shaped with the deepest part towards the coast. Due to the layering, the dynamics are baroclinic. The NCC will typically contain water with salinity less than 34.5 , and outside the NCC is the North Atlantic Current (NAC) with saltier water above 35 (Sætre 2007). Both the NCC and the NAC flow side by side northward along the Norwegian coast.

Inside the fjords, the water has typically a three-layer structure (Inall and Gillibrand 2010; Stigebrandt 2012). At the top is a thin brackish layer of $1-10 \mathrm{~m}$ depth. This layer is due to river runoff inside the fjord, and its extent and depth are dependent of the strength of the river discharge. In periods with little river discharge, this upper brackish layer will not be present. Also, in the outer parts of long fjords, the brackish layer might vanish due to various mixing processes. From the surface (or under the brackish layer) and down to the sill depth 
of the fjord is the so-called intermediate layer. This water is in good contact with the coastal water (Asplin et al. 1999; Asplin et al. 2013). Below the sill depth, for many fjords, are more stagnant water being replaced relatively seldom compared to the water above the sill depth (Gade and Edwards 1980; Inall and Gillibrand 2010).

The forcing of the water masses at the coast and in the fjords is very dynamic. Several forcing mechanisms are present and the most important are wind, tide, freshwater runoff, and internal pressure due to spatial differences in stratification (horizontal pressure gradients). Norway is in the path of the atmospheric polar front, and frequent strong wind episodes due to low pressure passages occur. The duration of these is typically modest, lasting for 1-2 days in an episodic manner (Parding et al. 2019). The tide consists of a Kelvin wave propagating along the Norwegian coast from south to north (Gjevik and Straume 1989). The M2 constituent is the leading mode. Amplitudes of sea level oscillations vary from $0.25 \mathrm{~m}$ in the south to $2 \mathrm{~m}$ in the north. Into the fjords, the tide will propagate as a barotropic wave, and topography and stratification can extract energy to mixing or to generate internal waves (Farmer and Freeland 1983; Stigebrandt 2012). In the deep and wide fjords, the current speed due to the tide will be modest. Differences in the stratification between the coast and the fjords can generate long internal waves in the intermediate water layer with an associated current which can be both relatively strong, have a large vertical extent and last for many days (Asplin et al. 1999; Asplin et al. 2013). Thus, such internal waves are the most important forcing for water exchange above sill level inside the fjords and between the coastal ocean and the fjords. Altogether, the various forcing mechanisms in combination with complex topography and the influence of the rotation of the Earth make the current vary on many scales both temporarily and spatially.

The environmental conditions along the Norwegian coast are suitable for cultivating Atlantic salmon. The temperature range is well suited for salmon growth; it is possible to find locations sheltered from the strongest winds and waves and the current is sufficiently strong for a constant supply of oxygen rich water to the many fish in the open net pens (Oppedal et al. 2011). During the last 40-50 years, the salmon aquaculture along the Norwegian coast has grown orders of magnitude worth more than 60 billion NOK in 2018 (Statistics Norway, www.ssb.no). About 1.3 million tons are produced annually in total at more than 1000 fish farms spread along the coast, of which 5-600 are in production at any time (https://www. fiskeridir.no/Akvakultur/Tall-og-analyse/Akvakulturstatistikktidsserier/Laks-regnbueoerret-og-oerret/Matfiskproduksjon). Such a large aquaculture industry comes with a cost for the environment with threats being escaping of farmed fish to the wild, discharge of effluents like feces, feed spill or other organic and inorganic matter, and transmission of diseases from farmed fish to the wild (Taranger et al. 2015).
The Norwegian Government has decided that the salmon aquaculture industry in Norway shall grow but only within sustainable limits, and the limiting factor now is the carrying capacity of the parasite salmon louse on the wild salmon stock (Ministry of Trade Industry and Fisheries 2015; Taranger et al. 2015). The Institute of Marine Research (IMR) is one of the institutions responsible for giving advice on environmental effects of aquaculture to the authorities, and how to quantify the carrying capacity of salmon lice on the salmonid wild fish populations has received a lot of attention in the latter 15 years (Asplin et al. 2013; Johnsen et al. 2014, 2016; Sandvik et al. 2016a, 2020; Skarðhamar et al., 2018; Myksvoll et al. 2018).

The salmon louse Lepeophtheirus salmonis is a natural parasite in Norwegian waters that feeds on the skin, fat, and mucus of salmonid fish (Pike \& Wadsworth 1999). With the industrialization of aquaculture, the numbers of potential hosts have increased, leading to unnaturally high lice infestations on both farmed and wild fish (Finstad et al. 2000; Bjorn et al. 2001; Heuch \& Mo 2001; Heuch et al. 2009, 2011; SerraLlinares et al. 2018). Salmon lice carry eggs in two eggstrings at the rear of the body. When these eggs hatch, the nauplii (lice larvae) are released in the water, where they go through two noninfectious nauplii stages before reaching the copepodite stage (Hamre et al. 2013). At this stage, they are able toand are crucially dependent on-infecting salmonid fish. During these stages, lice are planktonic and drift with the currents. Due to their relatively long planktonic phase of 13 weeks (Johnson and Albright 1991; Stien et al. 2005), information about the movement of the currents is crucial in order to determine the transport routes and residence areas.

In addition to a huge surveillance program for field observations (Serra-Llinares et al. 2014), the IMR has established a numerical modeling system estimating the abundance of salmon lice in time and space all along the Norwegian coast where the aquaculture industry takes place (Myksvoll et al. 2018). One challenge with the dispersion of salmon lice is the potential large advection distance during the planktonic phase, up to $\sim 100 \mathrm{~km}$ (Asplin et al. 2013). Thus, any current model must cover a fairly large area. The solution to collect sufficient information in time and space was to establish an implementation of the ROMS current model (http://myroms.org) for the whole Norwegian coast named the NorKyst800 (Albretsen et al. 2011). This is a compromise between spatial grid resolution to resolve dynamics and topography and geographical extension necessary to capture the full advective distance of the lice. The use of the ROMS as the current model is mainly for historical reasons. When it first was implemented at IMR, around 2000, it was assumed to be the best alternative. Ocean models using unstructured grid (finite element, finite volume), which could have been attractive alternatives due to their more flexible handling of the coast, were not sufficiently established at that time. The ROMS is also used by the Norwegian 
Fig. 1 The model domain of NorKyst 800 shown by the black rectangle in the map. Also included are the locations of coastal monitoring stations (red circles and corresponding names) and hydrography sections (magenta lines) regularly measured by the IMR. The four hydrographic transects are from South to North located in the Skagerrak (Torungen/NorwayHirtshals/Denmark), between Utsira/Norway and the Orkneys, Northwest of Svinøy/Norway and between Fugløya/Norway and the Bear Island

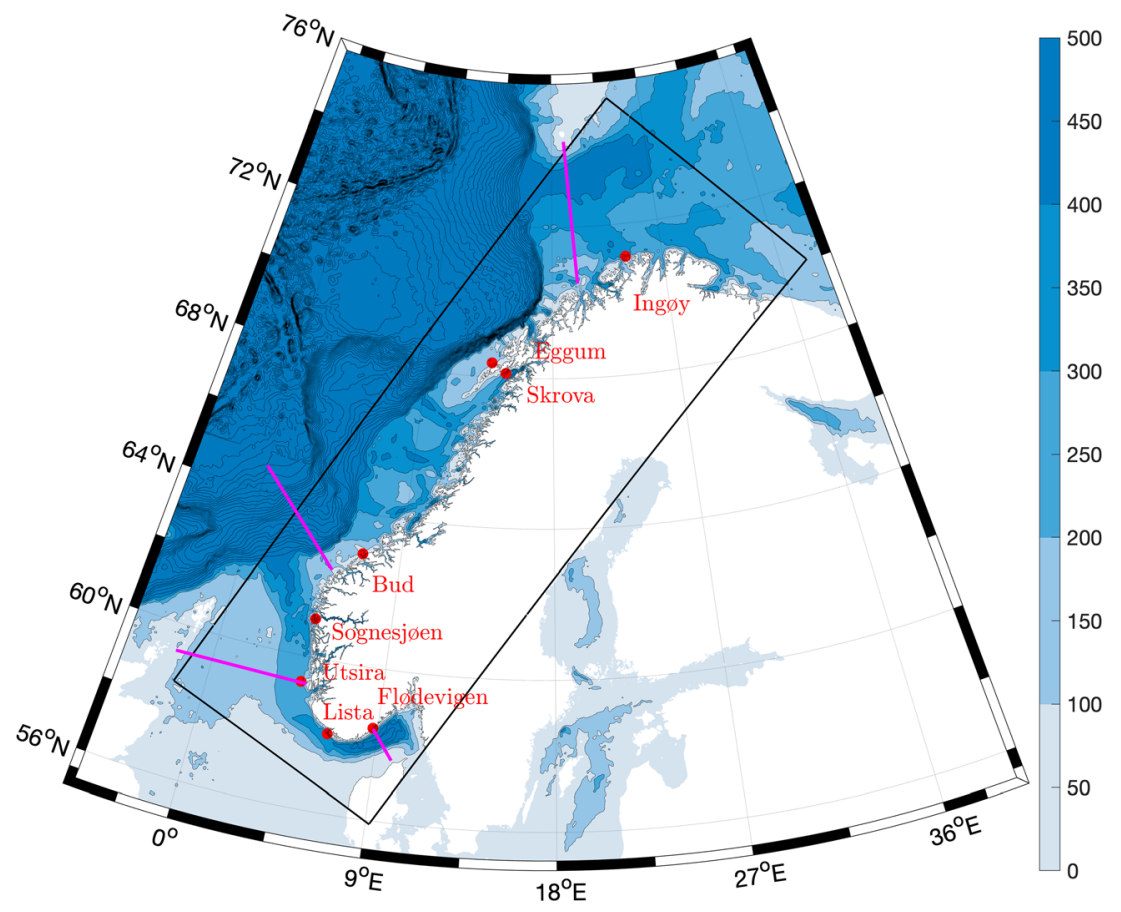

Meteorological institute which is a main collaborating partner for the IMR.

We will show that the NorKyst 800 model is a good application of this spatial compromise with results in good agreement with observations. Results from the NorKyst800 are important information for many management purposes in Norway. Especially the use of NorKyst800 to drive a model for dispersion of the salmon lice is important for Norwegian authorities. Furthermore, the Norwegian Meteorological institute is running NorKyst 800 daily producing a 66-h forecast (https://thredds.met.no), which represents a valuable asset for management agencies.

\section{Materials and methods}

\subsection{The salmon lice dispersion model}

\subsubsection{The current model}

We have used the Regional Ocean Current Model System (ROMS) as the hydrodynamical model embedded in the NorKyst800 system (e.g., Shchepetkin and McWilliams 2005; Haidvogel et al. 2008; or see http://myroms.org). In NorKyst800, we apply the sea ice module (Budgell 2005), but no kind of data assimilation is implemented. ROMS is a state-of- the-art, three-dimensional, free-surface, primitive equation numerical model using a generalized terrainfollowing s-coordinate in the vertical. The s-coordinate levels are adjusted according to the total water depth between the free surface and the bottom, keeping the same number of vertical coordinates for each horizontal grid cell. Our simulation applied s-levels with an enhanced resolution in the upper $\sim 50 \mathrm{~m}$ (the internal ROMS grid parameters were set equal to: Vtransform $=2$, Vstrething $=2$, theta_s $=8.0$, theta_b $=0.1$, and Tcline $=20$ ). Our simulation was initiated in January 1995 and presented here are results until 2018.

The bathymetry data were collected from the online data source, http://www.norgedigitalt.no, established by the Norwegian Mapping Authority, the Hydrographic service. The original resolution is about $50 \mathrm{~m}$ on an irregular grid. The coverage of Norge Digitalt data is for coastal zones only, and GEBCO_08 data (General Bathymetric Chart of the Oceans, http://www.gebco.net) were applied for the open ocean. The resolution of the GEBCO_08 global bathymetric grid is 30 arc-seconds, i.e., approximately $900 \mathrm{~m}$. The merged product of Norge Digitalt high-resolution bathymetry and GEBCO bathymetry was interpolated to the NorKyst 800 grid (see map of the model domain in Fig. 1). To avoid model instability and/or spurious deep currents, the final masked bathymetry was smoothed (Beckmann and Haidvogel 1993).

The high-resolution atmospheric fields used to force the NorKyst 800 model was provided by using the Weather Research and Forecasting model (WRF), developed by the National Center of Atmospheric Research (NCAR). The WRF model is a state-of-the-art numerical weather prediction model (Skamarock et al. 2008), and the implementation of the WRF model included a domain with horizontal grid resolution of $3 \mathrm{~km}$, covering slightly more than the NorKyst 800 domain. The model was initialized with an analysis (on a $0.25^{\circ} \times 0.25^{\circ}$ 
Fig. 2 The horizontal distribution of current at $10 \mathrm{~m}$ depth for August 1, 2018, simulated by the NorKyst 800 current model. The locations of current measurements at the coast and inside the Hardangerfjord are marked. The Current meter fjord location within the Hardangerfjord is named $\mathrm{HfjE}$

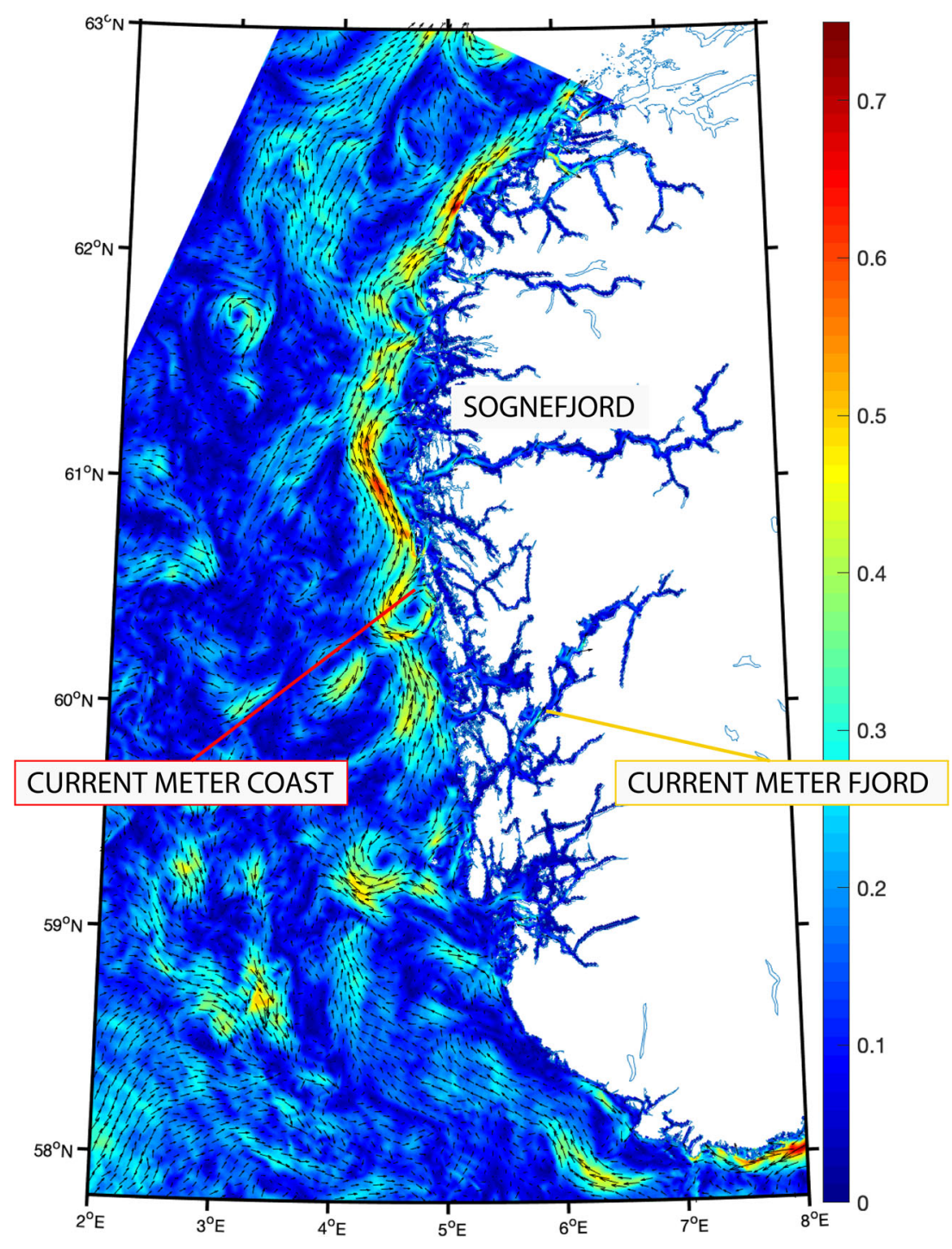

grid) of upper air and surface data from the European Centre for Medium Range Weather Forecasts (ECMWF), and lateral boundary values were updated every 6th hour during integration.

An important feature of the Norwegian coastal waters is the large supply of freshwater. From the Baltic sea, the net outflow is approximately $15,000 \mathrm{~m}^{3} / \mathrm{s}$ (Sætre 2007). The input of Baltic outflow is provided through the nesting conditions from the coarser model. From numerous rivers along the entire Norwegian coast, as much as $12,000 \mathrm{~m}^{3} / \mathrm{s}$ is discharged into the Norwegian Coastal Current. The river runoff in NorKyst 800 is based on modeled discharge from the 247 main Norwegian catchment areas that drain to the sea. The Norwegian river discharges are modeled by the NVE (Norwegian Water Resources and Energy Directorate) using a distributed version of the HBV-model with $1 \mathrm{~km}$ horizontal resolution (Beldring et al. 2003). Note that river discharges are estimated from natural variations in weather climate, and there are no modifications due to regulations by damming. Runoff values can then deviate from real discharge at some locations in cases where water is provided or restrained by dams. The outlets are positioned in the model grid at the location corresponding to the main river within the catchment area. In addition, the discharge is distributed linearly from the surface down to a prescribed depth for each river. This lower level of freshwater discharge varies with the total runoff, and the vertical shape of the runoff is kept constant throughout the model simulation.

As boundary conditions along the open boundaries, the model is forced by daily averaged currents, hydrography, and water level from a $4 \mathrm{~km} \times 4 \mathrm{~km}$ resolution ROMS hindcast simulation (details in Lien et al. 2014). The tidal forcing is applied along the open boundaries and interpolated from the global TPXO7.2 (Egbert and Erofeeva 2002). 

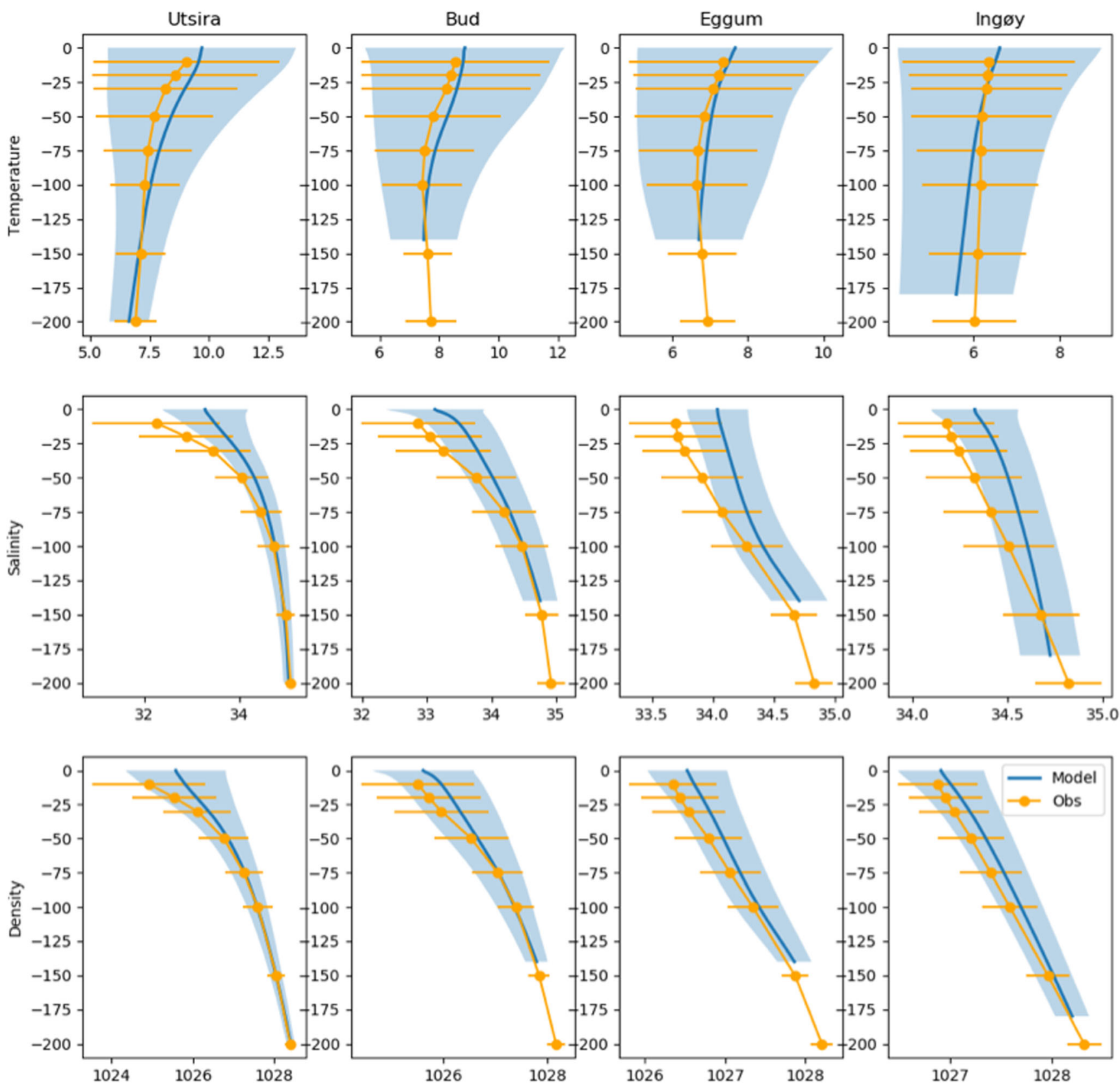

Fig. 3 Vertical gradient in temperature (upper row), salinity (mid row), and density (lower row) at 4 coastal stations from Utsira in the South to Ingøy in the North during a period of 20 years (1995-2015). Model results from diurnal means are shown in blue (mean values shown in

blue lines, standard deviations shown by the shaded areas), observations at $10,20,30,50,75,100,150$, and $200 \mathrm{~m}$ depth are shown by orange dots (mean values) and horizontal lines (standard deviations)

ROMS comes with a variety of lateral boundary conditions, including open, closed, and periodic (Marchesiello et al. 2001). The Flather boundary condition (Flather 1976) is used for the normal component of the barotropic velocity to incorporate deviations from the exterior values at the speed of the external gravity waves. The corresponding condition for surface elevation (Chapman 1985) assumes that all incoming signals are integrated consistently with the shallow-water wave speed. As described by Marchesiello et al. (2001) and as applied in our model set-up, ROMS has an option for providing radiation conditions on outflow and nudging to a known exterior value on inflow for 3D momentum and tracers. This is implemented as a variation on the radiation condition, requiring two timescales, namely the inflow nudging timescale and the outflow nudging timescale. Here, the nudging on inflow is 120 times larger than on the outflow. For vertical turbulence, the local closure scheme is based on the generic length scale (GLS) parameterization (Umlauf and Burchard 2003). 

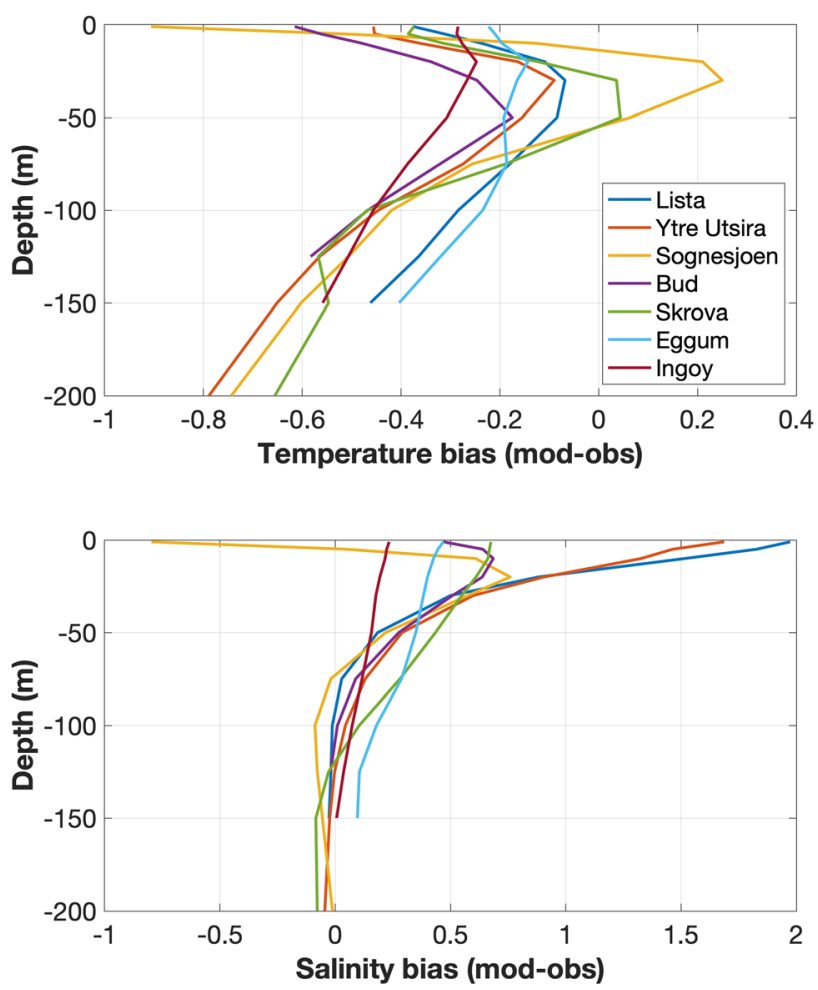

Fig. 4 The mean difference between modeled and observed temperature (upper panels) and salinity (lower panels) are shown for all coastal stations between Lista in the South and Ingøy in the North based on all available measurements between 1995 and 2016. The vertical axis

A 20-year archive of model results including hourly values of current and daily values of salinity and temperature will be subject for validation. Also, hourly values of both current and salinity and temperature from recent years (2017-2018) are evaluated.

\subsubsection{The source term for salmon lice}

The source term describes how many salmon louse nauplius stage 1 being hatched into the water masses at any time. There are more than one thousand registered salmon farming sites in Norway. In $5-600$ of these, there is ongoing production where reporting is mandatory (https://www.fiskeridir.no/Akvakultur/Tall-og-analyse/ Akvakulturstatistikk-tidsserier/Laks-regnbueoerret-ogoerret/Matfiskproduksjon). The weekly reports from farmers include water temperature and the average number of female lice on the fish.

The number of fish in the farms is reported monthly, and it is necessary to make an interpolation to weekly values. Based on these reports, we estimate the number of hatched nauplii using formulas in Stien et al. (2005). More details on these calculations can be found in Myksvoll et al. (2018).
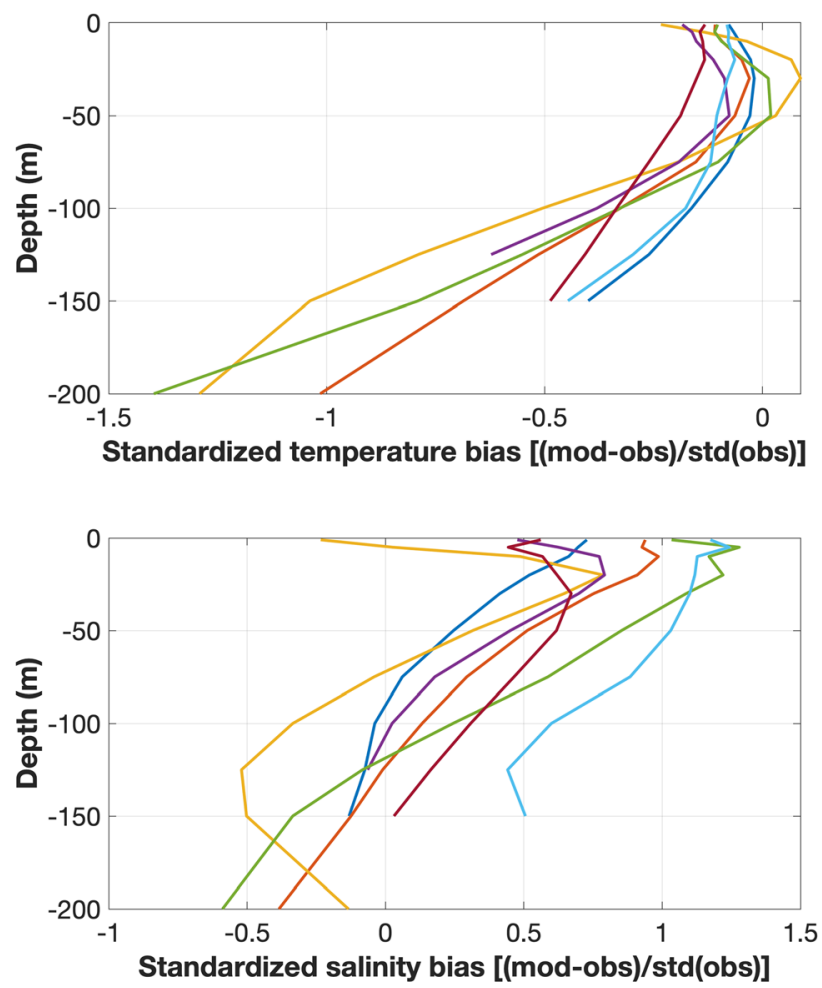

denotes depth (m). The panels to the right show the normalized model errors where the bias is divided by the standard deviation of the observed values. Values from each station are shown with different colors

\subsubsection{The particle tracking model}

Based upon the modeled hydrography and currents, the open access Lagrangian Advection and Diffusion Model (LADIM; https://github.com/bjornaa/ladim) is used to calculate the particle trajectories. The model solves the Lagrangian equation of motion, normally using a 4th-order Runge-Kutta scheme. In the vertical, the particles are given swimming behavior to mimic the observed behavior of salmon lice. The numerical lice in the model are given vertical velocity directed upwards when exposed to light levels over a critical value. A gradually avoidance of water masses with low salinity (2331 ) is also included (Sandvik et al. 2020). A vertical random walk is implemented to ensure variability between the particles and to represent small-scale turbulence. Detailed description of the model system can be found in Myksvoll et al. (2018) and Sandvik et al. (2020).

\subsection{The observations}

Current measurements (locations in Fig. 2) are made by acoustic Doppler profilers from the company Nortek. At the coast, a Nortek Signature 250 was used measuring upwards in the water column. The vertical cell size was 

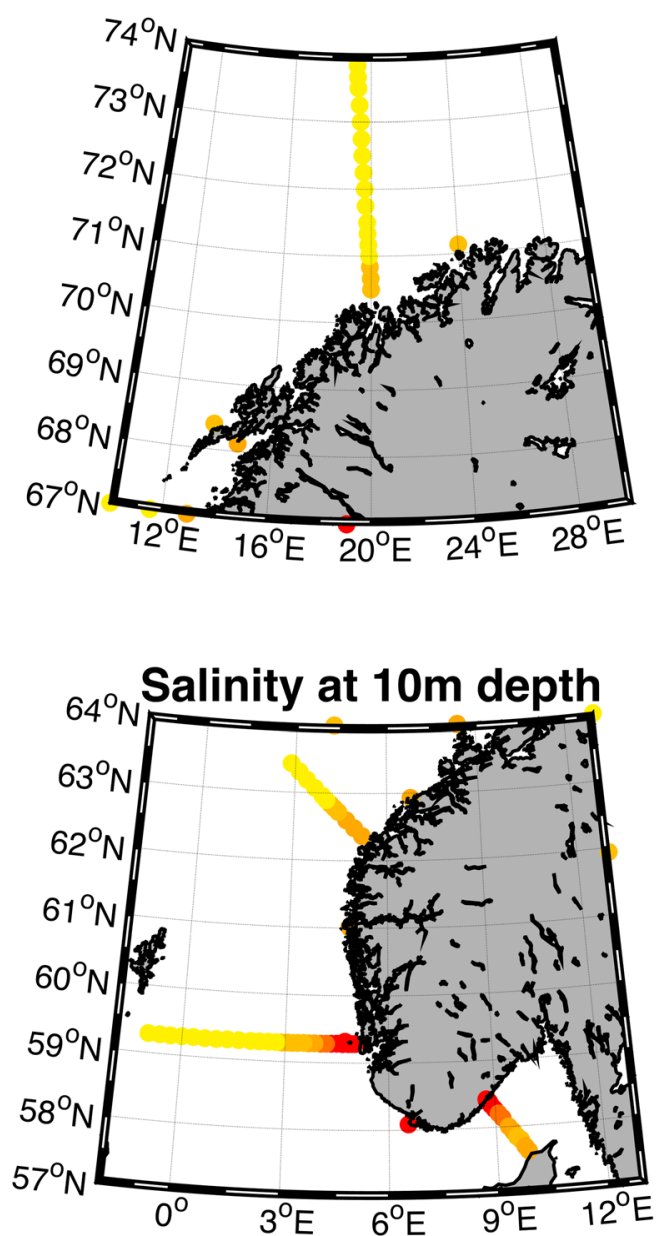

Fig. 5 The mean difference between modeled and observed salinities (left panels) and temperatures (right panels) at $10 \mathrm{~m}$ depth based on all measurements between 1995 and 2016. The coastal stations and the

$4 \mathrm{~m}$, the sampling interval $1800 \mathrm{~s}$ and the instrument depth was $100 \mathrm{~m}$. Inside the fjord, a Nortek Aquadopp $600-\mathrm{kHz}$ Z-cell profiler was used, also measuring upwards. The vertical cell size was $1 \mathrm{~m}$, the sampling interval $600 \mathrm{~s}$, and instrument depth $30 \mathrm{~m}$. More details of the current meters can be found at https://www. nortekgroup.com/.

Measurements of salinity and temperature inside Hardangerfjord were made in connection with regular cruises by "RV Hans Brattstrøm." A SAIV SD204 mini CTD (http:// www.saivas.no) was used at seven occasions in 2018. The SAIV SD204 has a sampling frequency of $1 \mathrm{~Hz}$.

The hydrographic properties in NorKyst 800 are evaluated against the measurements from IMR's fixed coastal stations (see, e.g., Albretsen et al. (2012) and available data from http://www.imr.no/forskning/forskningsdata/ stasjoner). Vertical temperature and salinity profiles are measured 2-4 times per month by local observers and time series are available from the 1940s. Recently, the SAIV SD204 has been used. In addition, profiles from IMR's
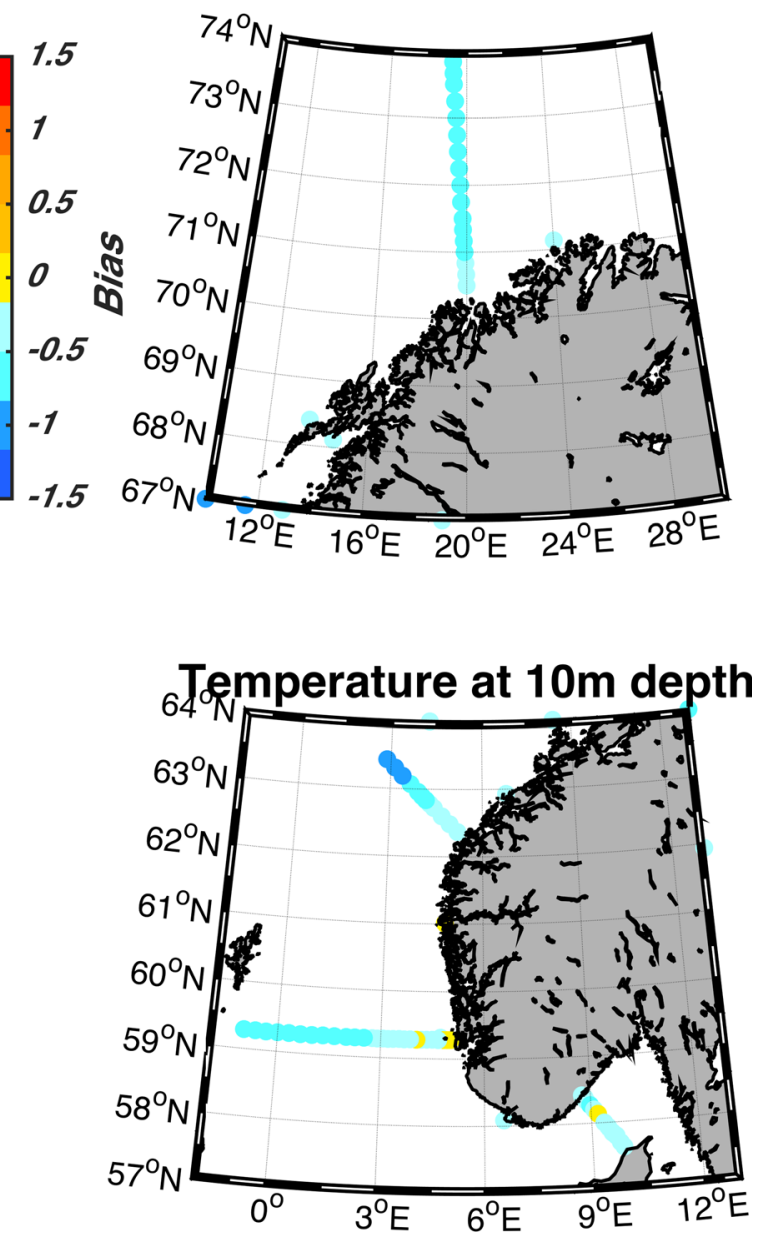

hydrographic transects are considered. The orange/red and blue colors denote if the model overestimate or underestimate the values, respectively. Yellow colors indicate an unbiased model

standard hydrographical sections across the Skagerrak (10-12 times per year), Utsira-Orkneys (4-5 times per year), off Svinøy (4 times per year), and Fugløya-Bear Island (4 times per year) are applied to validate NorKyst 800 for the surface waters (1-10 m depth) and the Atlantic waters (150 m depth is applied). The locations of the coastal stations and the hydrographical transects are shown in Fig. 1.

With the purpose of mapping the infestation level of salmon lice during the wild post-smolt migration of wild Atlantic salmon, open net-pen sentinel cages were positioned in selected areas each containing 30 farmed post-smolts. The fish in the sentinel cages were replaced after 14 days. Salmon lice were counted and categorized for each fish individually. Salmon lice were also observed on captured wild fish (both salmon and sea trout), but the sentinel cages are considered as the most suitable observation for model evaluation, due to the known exposure time and position (Sandvik et al. 2016a; Sandvik et al. 2020). 

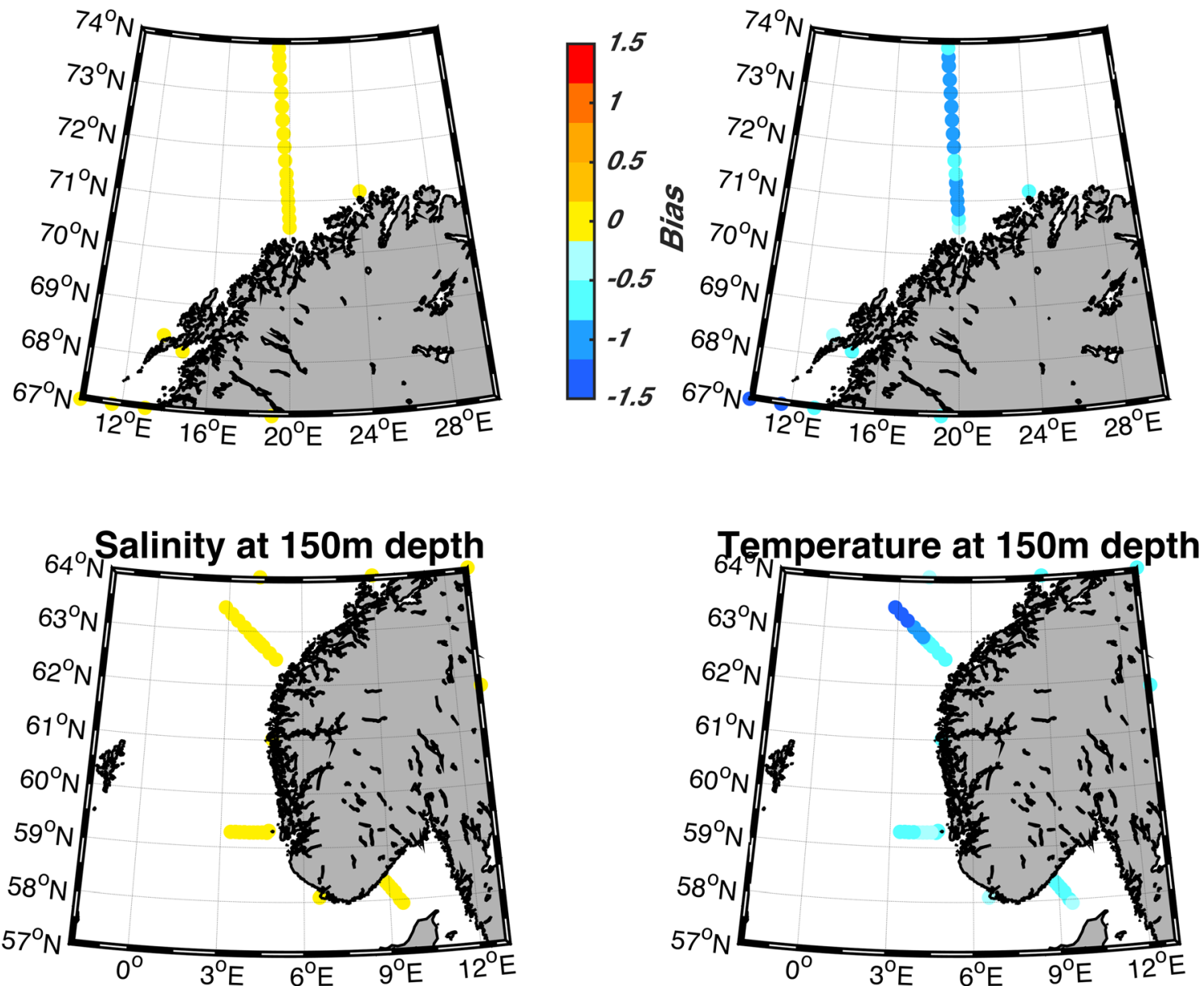

Fig. 6 The mean difference between modeled and observed salinities (left panels) and temperatures (right panels) at $150 \mathrm{~m}$ depth based on all measurements between 1995 and 2016. The coastal stations and the

hydrographic transects are considered. The orange/red and blue colors denote if the model overestimate or underestimate the values, respectively. Yellow colors indicate an unbiased model
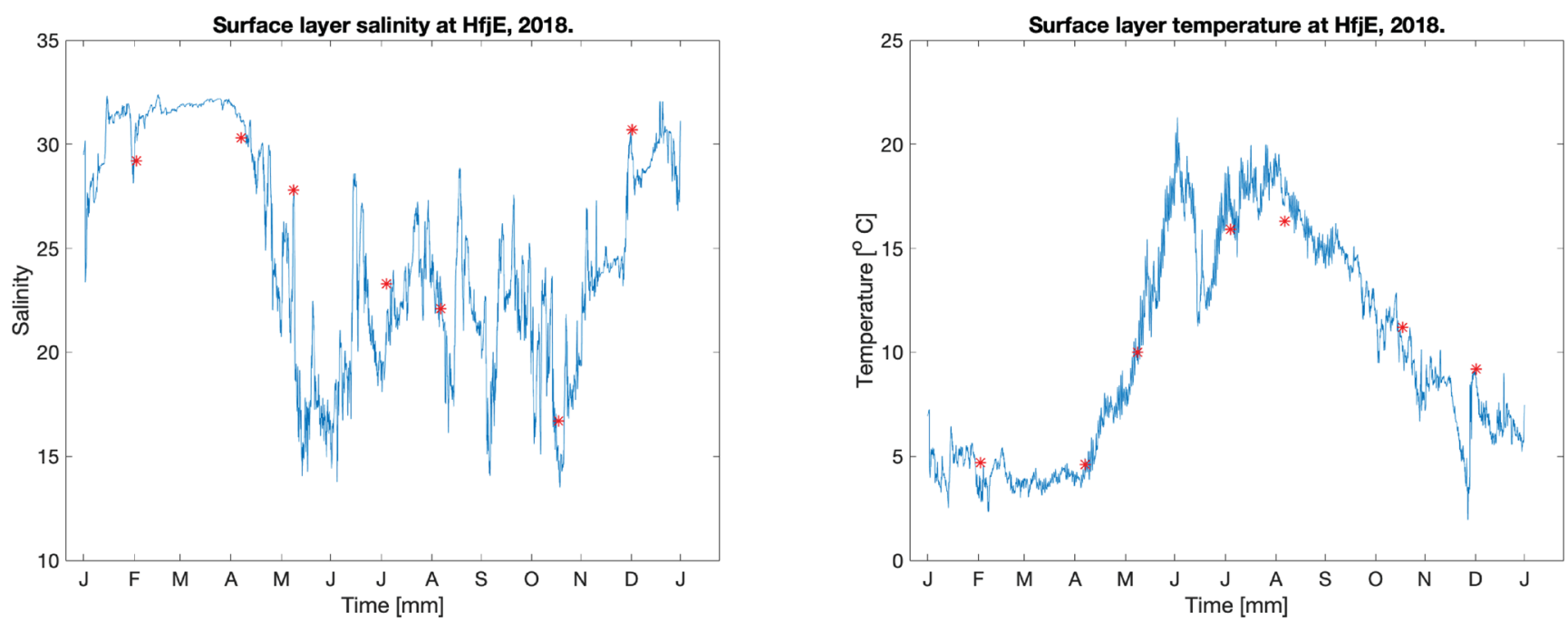

Fig. 7 Time series of modeled salinity (left panel) and temperature $\left({ }^{\circ} \mathrm{C}\right)$ (right panel) at the surface layer from NorKyst800 for 2018 at the position $\mathrm{HfjE}$ in the middle of the Hardangerfjord. Observations from $\sim 0.5 \mathrm{~m}$ depth are marked by red stars 

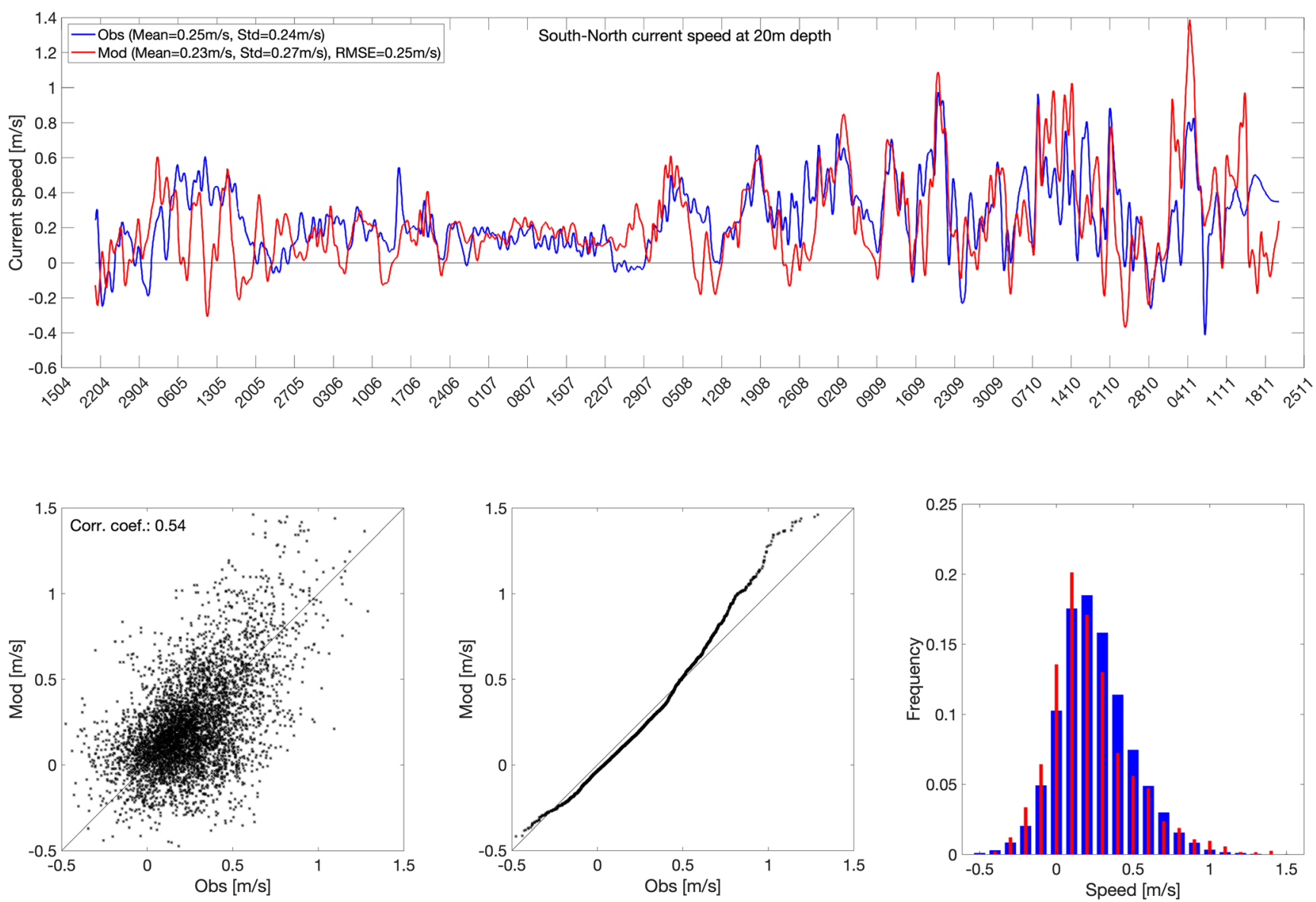

Fig. 8 Time series of 24-h low-pass filtered modeled and observed North-South current at $20 \mathrm{~m}$ depth (top), a scatter plot (bottom left), a quantilequantile plot (bottom middle), and a histogram (bottom right) from the coastal location

\section{Current model validation}

Our validation analysis is presented where the current model results are compared with available observations of both current, salinity, and temperature. We have done this for both coastal areas and fjord areas inside the Hardangerfjord, which is a representative fjord of medium to large size.

\subsection{Hydrography at the coast}

The coastal stations with hydrographic measurements approximately 2-4 times per month act as a solid basis for evaluating the seasonal and interannual deviations in the hydrodynamic model. It is vital to have a coastal model which is capable to reproduce the fluctuating density field along the coast as this has major importance in deciding the direction and magnitude of along-fjord transports. In addition, a well-defined density field will also act as valuable information for describing the physical conditions.

The salinities observed at the coastal stations show water masses with relatively low values along the coast. The 20-year average temperature along the coast from the south to the north decreased from close to $9{ }^{\circ} \mathrm{C}$ at $10 \mathrm{~m}$ at Utsira, to $6{ }^{\circ} \mathrm{C}$ at Ingøy (Fig. 3). The temperatures have significant seasonal fluctuations, increasing in magnitude close to the surface. The water column is strongly stratified, especially during spring and summer with positive heat flux from the atmosphere to the ocean and peak run-off from land. The stratification of the water column is stronger in the south compared to the north, both according to salinity and temperature. The modeled hydrography from the 20-year archive of NorKyst 800 results is successfully able to reproduce the vertical temperature gradient within $1{ }^{\circ} \mathrm{C}$ precision, including seasonal variability. The vertical salinity gradient is underestimated by the model, showing too high salinity of the water above $\sim 125-150 \mathrm{~m}$ depth and slightly underestimating the salinity below. In the upper $20 \mathrm{~m}$ of the water column, the salinity is approximately one standard deviation higher than the observed mean. This offset is decreasing down to a minimum at about $125-150 \mathrm{~m}$ depth.

A closer look at the model bias in temperature and salinity is shown in Fig. 4. For temperature the model is about 0.2- 

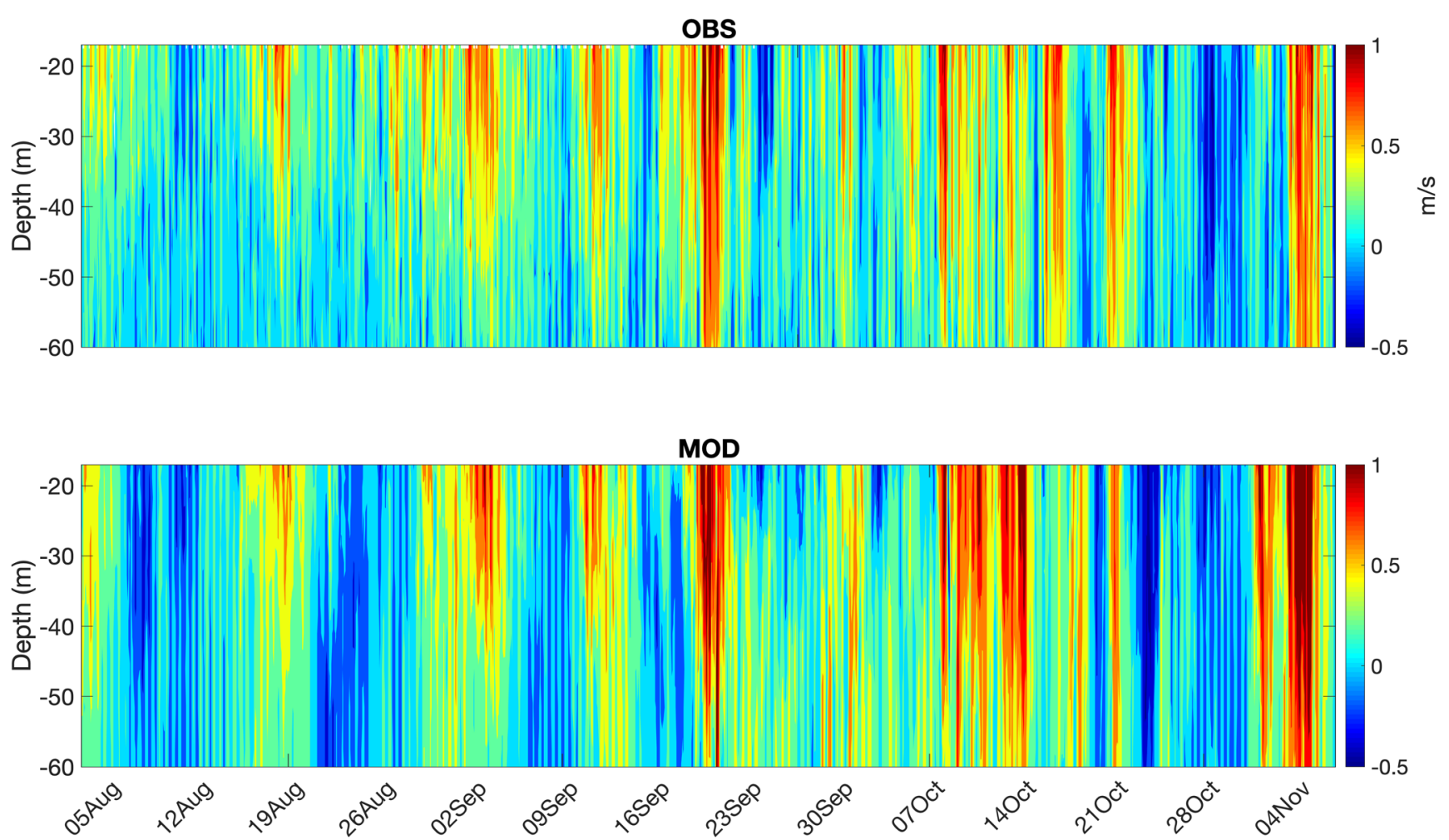

Fig. 9 Time series of $24 \mathrm{~h}$ low-pass filtered time series of modeled and observed north-south current between 17 and $60 \mathrm{~m}$ depth at the coastal location

$0.5^{\circ} \mathrm{C}$ too cold in the upper $100 \mathrm{~m}$ and exaggerates the cold bias slightly further down. The upper $50 \mathrm{~m}$ salinities are mainly too high in the model, but the magnitude varies between the locations. The model overestimates the surface salinity at the southernmost stations, Lista and Utsira, while the model has slightly too low surface salinity at Sognesjøen.

The hydrographic variability along the Norwegian coast is highest in the Skagerrak and decreases northward. The standard deviation from the observations and the model results are very similar (not shown), and the model biases in Fig. 4 have also been scaled with the standard deviations to give estimates of a standardized model error. The long-term standardized model error in temperature for the upper $100 \mathrm{~m}$ is then very small, and with a negative increase down to $200 \mathrm{~m}$. The standardized model error in salinity is mainly within the range from -0.5 to 0.5 with some variations between depths and locations.

We have also evaluated the model against the standard hydrographical sections maintained by the IMR to detect if there are any spatial offsets in the density field. The longterm model error at $10 \mathrm{~m}$ depth, representing the surface waters, is shown in Fig. 5. We clearly see that the overestimated surface salinities are mainly confined within the Norwegian Coastal Current off the southern Norway, and that model error is reduced considerably in offshore regions. Regarding surface temperatures, the model is slightly too cold all over the model domain. The long-term model error at 150-m depth, representing the Atlantic waters, is shown in Fig. 6. We see that the deep-water salinities are near unbiased in all regions and that the model is too cold, particularly close to the deepest parts of the Norwegian Sea.

\subsection{Hydrography in fjords}

Inside the fjords, we have compared surface salinity ( $0.5 \mathrm{~m}$ depth) at the location in the middle of the Hardangerfjord (see location in Fig. 2). The time series of hourly values of salinity from NorKyst 800 shows values above 30 until the spring, a gradual decrease of value down to about 20 in the summer and with increase again up to above 30 in the late fall (Fig. 7). In the meantime, there are episodes with values below 15 and above 25. The observations from seven cruises have a good fit with the model results, and all measurements either represent a long-term normal value or a shorttime fluctuating value.

The seasonality of the surface temperature within the Hardangerfjord typically starts with cold water of about $5{ }^{\circ} \mathrm{C}$ (in 2018) until late spring, then an increase up to between 15 and $20^{\circ} \mathrm{C}$ in the summer and a decrease through the fall down to cold water again (Fig. 7). The daily-weekly variability of the temperature is less pronounced than for the salinity, mostly within $1-2{ }^{\circ} \mathrm{C}$. As for salinity, the observations have a good fit with the model results. 

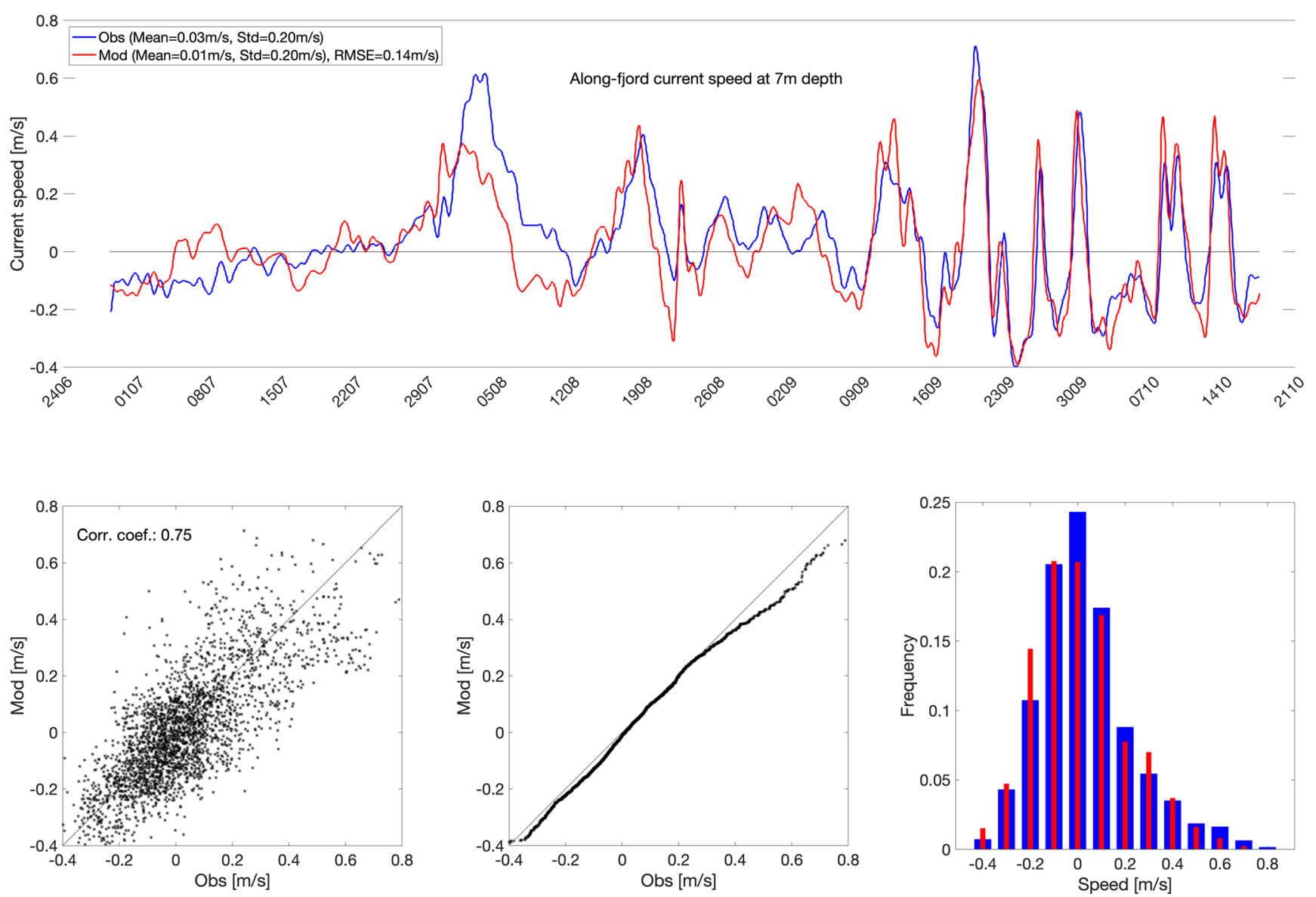

Fig. 10 Time series of $24 \mathrm{~h}$ low-pass filtered modeled and observed along fjord current at $7 \mathrm{~m}$ depth (top), a scatter plot (bottom left) a quantile-quantile plot (bottom middle) and a histogram (bottom right) from the fjord location

\subsection{Currents at the coast}

For comparison of current, we have data from one location at the coast outside Bergen and one location inside the Hardangerfjord (see map in Fig. 2). For the coastal location, currents were measured between April and November 2018. We use values from approximately $20 \mathrm{~m}$ depth and the component along the North-South direction for comparison. This represents the uppermost level measured by the current meter. The directions north-south is close to the main flow direction. We omit the high-frequency tidal flow in the presentation and filter the time series with a 24-h 4th-order Butterworth low-pass filter. The comparison (between the full time series including the tides) is presented by displaying time series of north-south current speed, scatter plot, quantile-quantile plot, and a frequency histogram (Fig. 8). We illustrate the time series with $24 \mathrm{~h}$ low-passed values (de-tided) while all other figures and values are based on a time resolution of $1 \mathrm{~h}$. The comparison shows good agreement. There are episodes not captured by the numerical model, but the mean flow only differs by $0.02 \mathrm{~m} \mathrm{~s}^{-1}$ $\left(0.25 \mathrm{~m} \mathrm{~s}^{-1}\right.$ vs. $\left.0.23 \mathrm{~m} \mathrm{~s}^{-1}\right)$ and the standard deviation by $0.03 \mathrm{~m} \mathrm{~s}^{-1}\left(0.24 \mathrm{~m} \mathrm{~s}^{-1}\right.$ vs. $\left.0.27 \mathrm{~m} \mathrm{~s}^{-1}\right)$. The root mean square error is $0.25 \mathrm{~m} \mathrm{~s}^{-1}$. Although the mean speed for the entire measuring period is slightly underestimated in the model, we find that the model slightly overestimates the highest speeds towards the North. The latter can be attributed to a few episodes at the end of the period.

The vertical structure between 20 and $60 \mathrm{~m}$ depths also indicate a good fit between the observed and modeled northsouth current component (Fig. 9).

\subsection{Currents inside the fjord}

Inside the fjords, we compare the 24-h low-passed flow component in the along-fjord direction at approximately $7 \mathrm{~m}$ depth (Fig. 10). Positive values represent flow into the fjord. In a fjord, the mean flow for a longer period will be small since almost equal amounts of water will flow into and out of the fjord in a series of episodes lasting typically some days. In this case, the mean flow at $7 \mathrm{~m}$ depth is $0.03 \mathrm{~m} \mathrm{~s}^{-1}$ from the observation and $0.01 \mathrm{~m} \mathrm{~s}^{-1}$ from the model results, implying that there is a small net inflow at this level and location. The standard deviation of the current speed is comparable to the mean speed of the flow and equal for both the observation and 


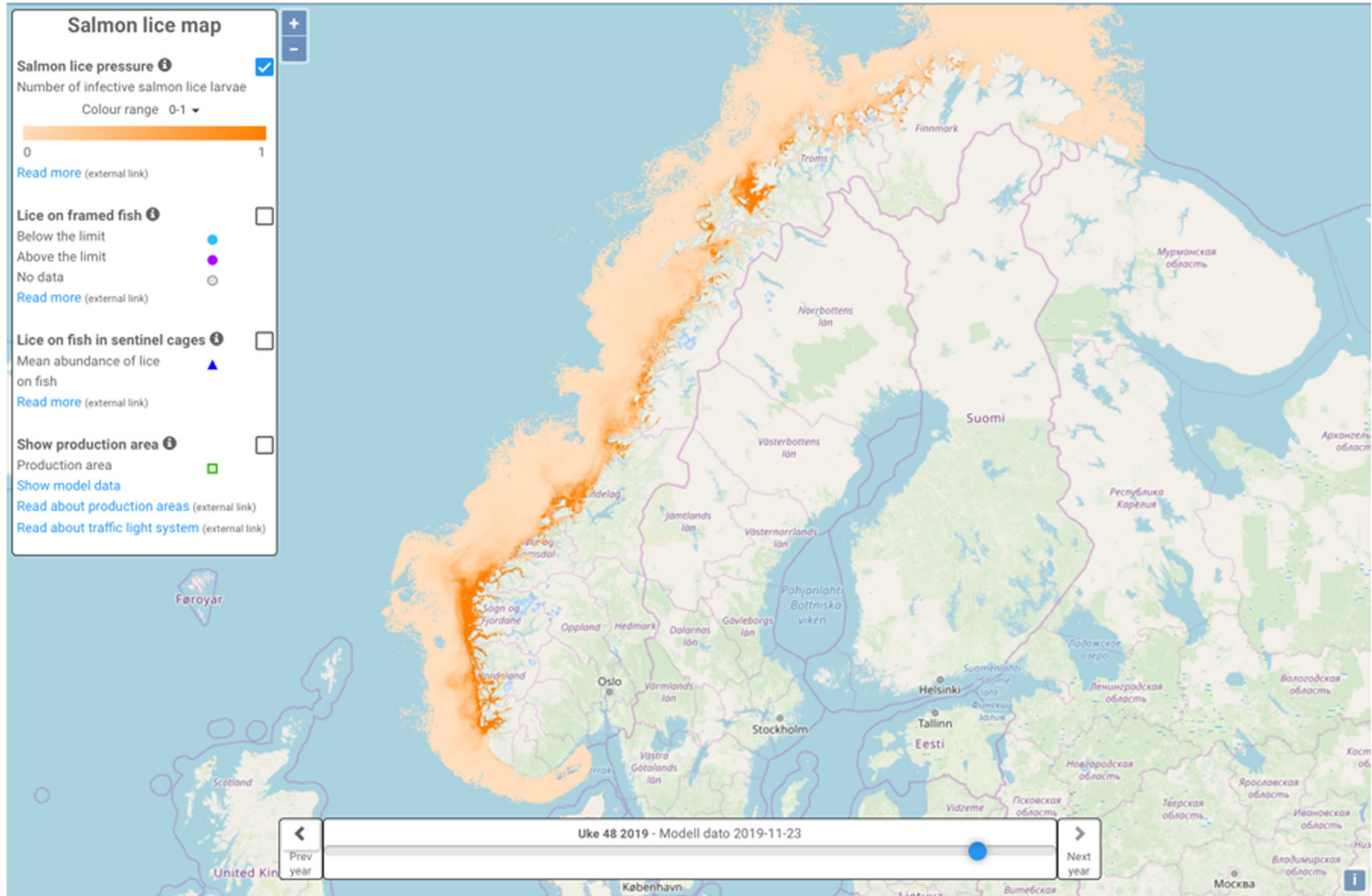

Fig. 11 Screendump of the web page http://lakselus.no where the weekly nowcasts of salmon lice copepodite abundance along the Norwegian coast are presented. Illustrated here is the distribution for week 48 of 2019

the model result $\left(0.20 \mathrm{~m} \mathrm{~s}^{-1}\right)$. The numerical model underestimates the strongest inflow, due to some episodes in September and October.

\section{Salmon lice dispersion}

Every week, an updated view of the abundance of salmon lice copepodites is presented on the web page http://lakselus.no (Fig. 11). This is a result of 40-day dispersion simulation of planktonic salmon lice from all salmon farms in production along the entire Norwegian coast. The mean value for the last 10 days of salmon lice copepodites in the whole water column is presented.

To illustrate the importance of detailed information of the current, we will present results from the salmon lice model from the Sognefjord in spring 2017. The Sognefjord is the largest fjord in Norway, and the abundance of salmon lice in the spring 2017 was monitored by sentinel cages as part of the national surveillance program. The number of lice on the fish in the sentinel cages for the first measuring period (May 10-
24) was low in the two innermost positions of the fjord, and slightly higher further out (Fig. 12, upper panel). For the second period (May 24 to June 8), we found a large increase of lice on the fish in the innermost cages (Fig. 12, lower panel), and we will demonstrate how episodic, near-surface, inward currents explain this advection of salmon lice.

Based on fish farmers reports, the highest production of salmon lice nauplii were mostly concentrated in the mouth region of the Sognefjord. Additionally, also the two innermost farms had some nauplii production (Fig. 13). There are no farms in the inner part of the fjord.

Time series of model results from a location in the outer mouth region and a location in the inner part adjacent to the innermost sentinel cages (positions marked by stars in Fig. 12) show that until the middle of May there were only copepodites at the outer location (Fig. 14). Then, a substantial increase of copepodites occurs in the outer part followed by an increase also in the inner part a week later around May 23. This increase in the inner part is due to an advection of copepodites from the outer part, as illustrated from the horizontal distribution of copepodites at May 21 and May 23 (Fig. 15). 

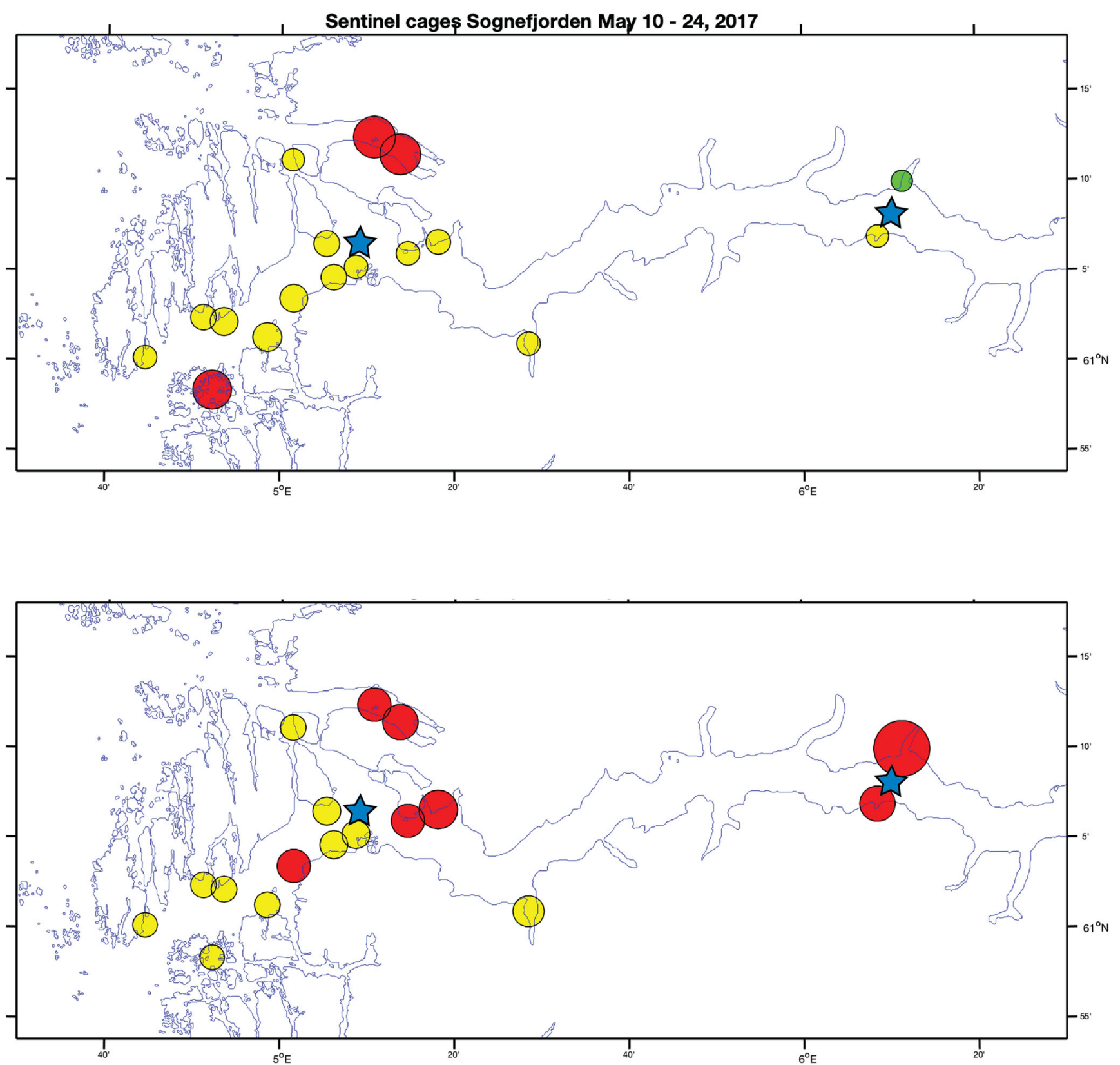

Fig. 12 Abundance of salmon lice on the fish in sentinel cages for two periods in May-June 2017. Top figure shows the first period (May 10 to 24 ), and the bottom figure shows the last period (May 24 to June 8). Green colored circles indicate average number of lice on the fish less than

\section{Discussion}

Numerical current model results validation is not an objective exercise, and a never-ending effort should be made to continuously check the results (Dee 1995). Usually model validation consists of comparing model results with available observations. A numerical current model can produce good results while standard statistical error metrics as rootmean-square or cross-correlation compared to observed currents still can be large (Ziegler et al. 2012). The reason is the
1, yellow less than 10 and red more than 10 lice. Larger circle size indicates more lice. The blue stars show the locations where model time series are extracted from

large number of temporal and spatial oscillations that make up ocean currents, and that these oscillations can be slightly out of phase in the model results compared to observations. Such a situation, with a narrow branch of current close to a current meter location, can be seen in the model results of currents outside the Western Norway (Fig. 2). We find a relatively high RMSE value of $0.25 \mathrm{~m} \mathrm{~s}^{-1}$ for this location. Oceanographic observations are normally accurate but sparse in space and/or time, while hydrodynamic models are relatively continuous but with unknown error terms. 


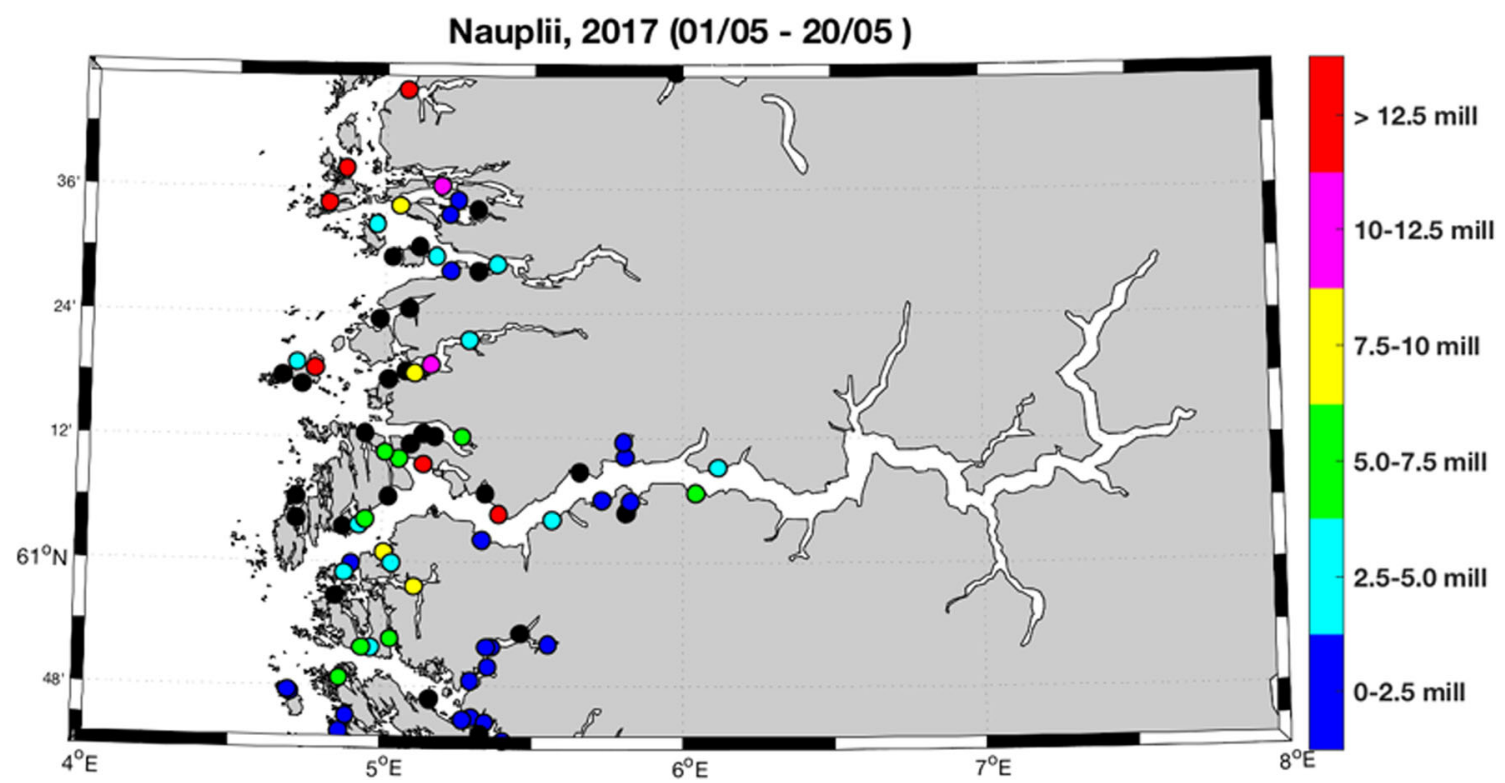

Fig. 13 Nauplii production at fish farms in the Sognefjord between May 1 and 20. Black dots represent farm locations without production

This issue has been further discussed and exemplified for the Ingøy station (Sandvik et al. 2016b).

Our results indicate that NorKyst800 compare reasonably well both with observed hydrography as well as currents. The deviation is typically within a unit of salinity and $1{ }^{\circ} \mathrm{C}$ of temperature. Also, the variability of the observations is captured well by the model results. The simulated currents are realistic with a consistent match with the observations, and with only a few episodic deviations.

Since the variability of the model results compare well with the observed variability, we can conclude that the model results are realistic and describe something that can happen in nature. Thus, the model results are useful in investigations of general properties as, e.g., connectivity between locations (Samsing et al., 2018). The model results are often good at predicting conditions at a given time, but due to occasional episodic misfit between observed and modeled currents, we cannot trust the model results completely. Hence, this demonstrates that additional current observations should be performed continuously along with model simulations as an independent quality check.

The reason for the deviations between modeled and observed current is most likely due to limitations in the forcing applied. Typically, the failing of the model to reproduce the observed short but strong inflow events to the Hardangerfjord in September (Fig. 10) is probably due to discrepancies in the wind forcing and/or deviations in the offshore density and momentum field.

We find that the horizontal grid resolution of $800 \mathrm{~m} \times$ $800 \mathrm{~m}$ is sufficient to capture the physical conditions

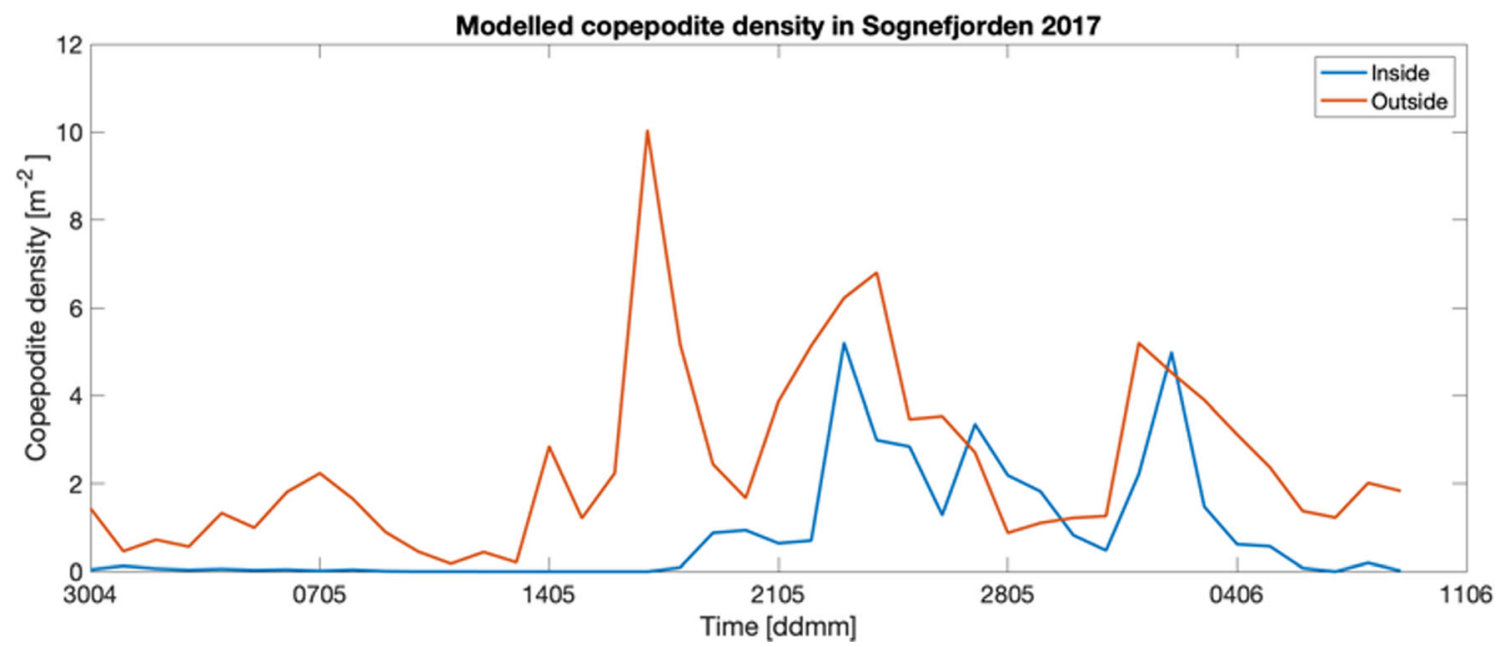

Fig. 14 Time series of modeled copepodite density $\left(\mathrm{cop} \mathrm{m}^{-2}\right)$ from two positions in the Sognefjord marked by red stars in Fig. 12 


\section{Copepodite density $\left[\mathrm{m}^{-2}\right]$ upper $2 \mathrm{~m}$ for 21-May-2017}

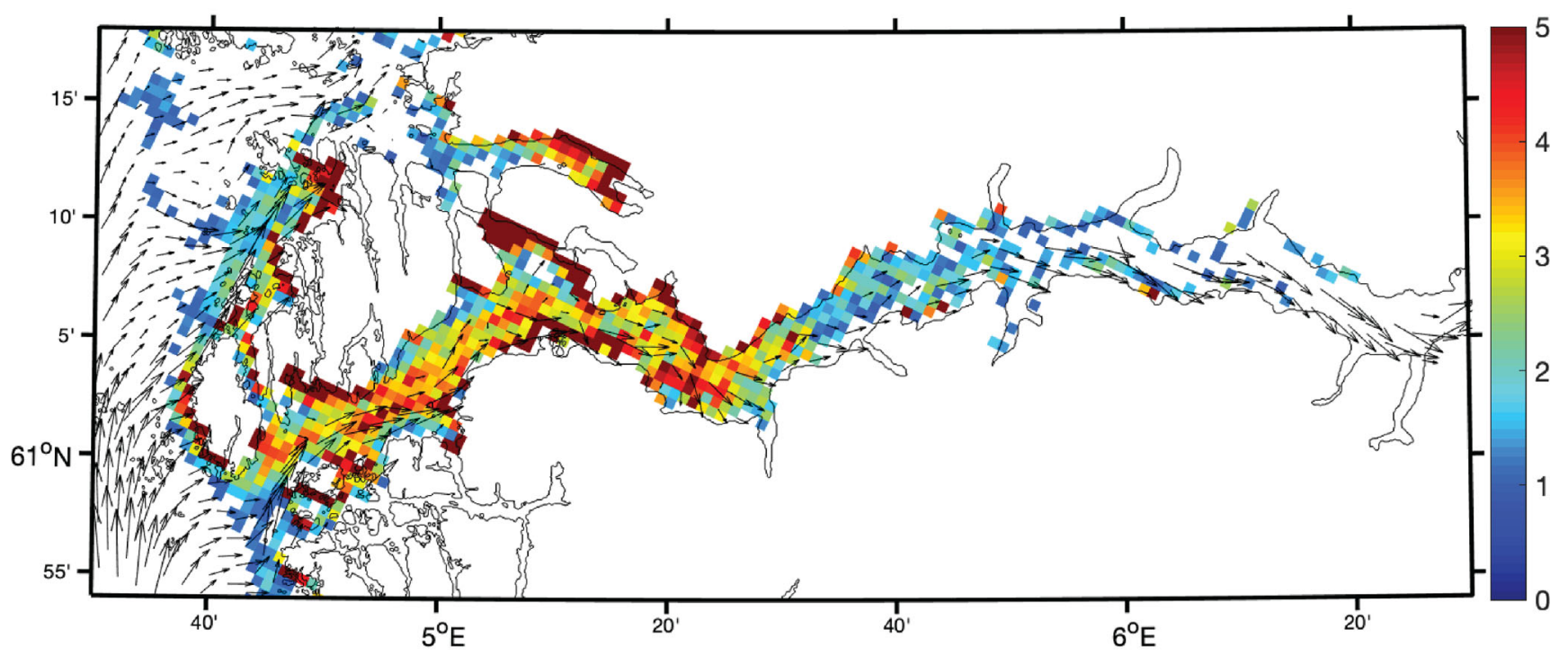

\section{Copepodite density $\left[\mathrm{m}^{-2}\right]$ upper $2 \mathrm{~m}$ for 23-May-2017}

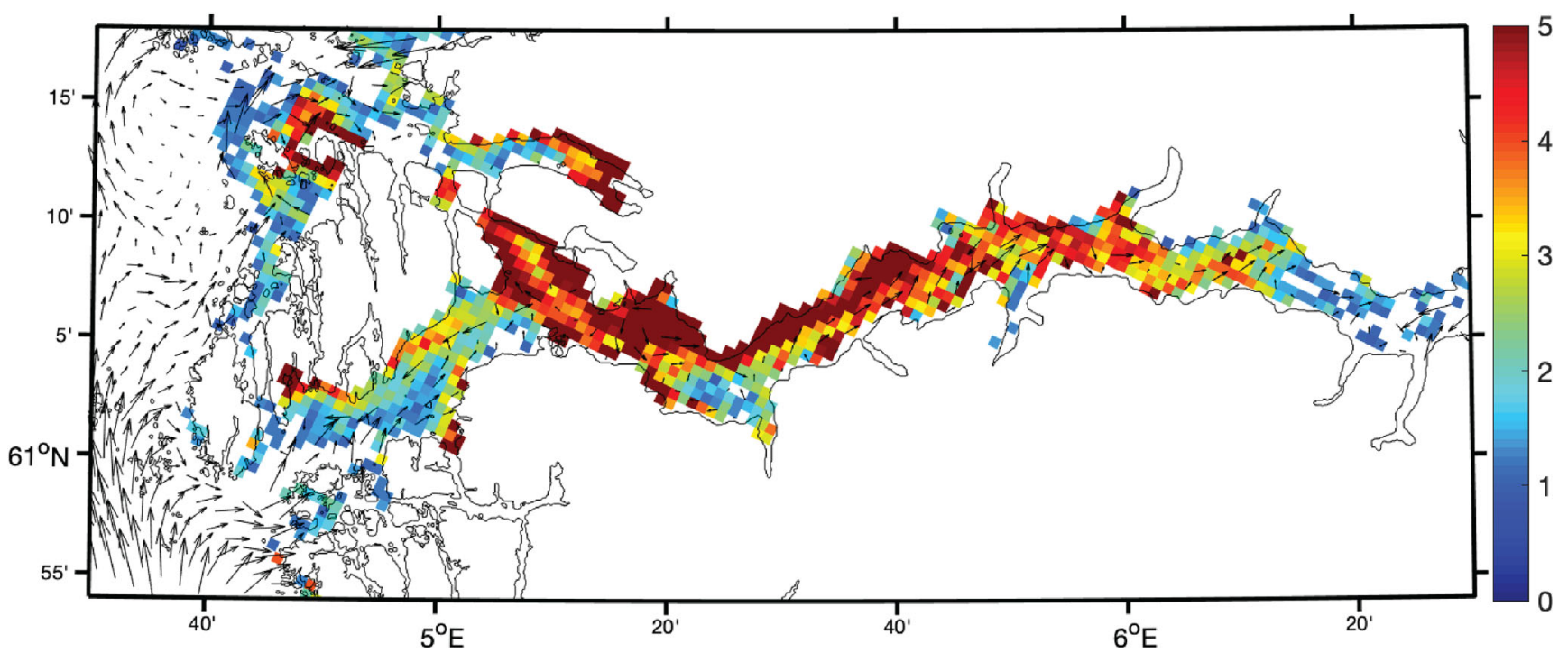

Fig. 15 Simulated distribution of copepodites at May 21 and May 23, 2017, in the Sognefjord. The arrows represents the daily mean surface current as calculated by the NorKyst 800 model

reasonably well. Only in areas with narrow topography we will need a higher resolution. A modification of the NorKyst800 named NorFjords 160 contains 13 subareas covering the whole coast of Norway with $160 \mathrm{~m} \times 160 \mathrm{~m}$ horizontal resolution and otherwise identical settings as NorKyst800. Occasionally, we need to do an extra simulation with the NorFjords 160 to reproduce transport patterns in more narrow parts of the coast. However, the higher resolution model covering the entire Norwegian coast is $\sim 50$ times more demanding in terms of computational cost.

The presented results from salmon lice dispersion in the Sognefjord clearly illustrates that detailed information of current is needed to be able to describe the abundance of the lice. From the observations of the currents (Figs. 9 and 10), we see 
that numerous episodes of several days duration occur. Given that the length of the water borne stages of the salmon lice are two to 3 weeks, the individual louse might experience several current states during its drift and the resulting dispersion pattern will accordingly be variable.

As a final remark, we are satisfied with the good comparison between the results of the NorKyst 800 and available observations. This model implementation has got an important role as source of physical oceanographic information in Norway, and it is crucial that the results can be trusted.

Acknowledgments This research combines work from various projects, including the Institute of Marine Research internal Fjord and coastal climate project (internal project no. 14894), the Salmon lice surveillance program funded by the Norwegian Department of Trade, Industry and Fisheries (internal project no. 14650), MORMOR (intenal poject no. 15197), and Coast-risk project funded by the Norwegian Research Council (project no. 299554). The ocean model simulations were performed on resources provided by UNINETT Sigma2 - the National Infrastructure for High Performance Computing and Data Storage in Norway. Thanks to the crew on the research vessels collecting data and to the Norwegian Meteorological institute running NorKyst 800 every day.

Funding information Open Access funding provided by Institute of Marine Research.

Open Access This article is licensed under a Creative Commons Attribution 4.0 International License, which permits use, sharing, adaptation, distribution and reproduction in any medium or format, as long as you give appropriate credit to the original author(s) and the source, provide a link to the Creative Commons licence, and indicate if changes were made. The images or other third party material in this article are included in the article's Creative Commons licence, unless indicated otherwise in a credit line to the material. If material is not included in the article's Creative Commons licence and your intended use is not permitted by statutory regulation or exceeds the permitted use, you will need to obtain permission directly from the copyright holder. To view a copy of this licence, visit http://creativecommons.org/licenses/by/4.0/.

\section{References}

Albretsen J, Sperrevik AK, Staalstrøm A, Sandvik AD, Vikebø F, Asplin L (2011) NorKyst-800 report no. 1: User manual and technical descriptions. IMR Res Rep Ser Fisken og Havet 2/2011. Institute of Marine Research, Bergen

Albretsen J, Aure J, Sætre R, Danielssen DS (2012) Climatic variability in the Skagerrak and coastal waters of Norway. ICES J Mar Sci 69(5): 758-763

Asplin L, Salvanes AGV, Kristoffersen JB (1999) Nonlocal wind driven fjord-coast advection and its potential effect on plankton and fish recruitment. Fish Oceanogr 8:255-263

Asplin L, Johnsen IA, Sandvik AD, Albretsen J, Sundfjord V, Aure J, Boxaspen KK (2013) Dispersion of salmon lice in the Hardangerfjord. Mar Biol Res 10:216-225. https://doi.org/10. 1080/17451000.2013.810755

Beckmann A, Haidvogel DB (1993) Numerical simulation of flow around a tall isolated seamount. Part I: problem formulation and model accuracy. J Phys Oceanogr 23:1736-1753
Beldring S, Engeland K, Roald LA, Sælthun NR, Voksø A (2003) Estimation of parameters in a distributed precipitation-runoff model for Norway. Hydrol Earth Syst Sci 7(3):304-316

Bjorn PA, Finstad B, Kristoffersen R (2001) Salmon lice infection of wild sea trout and Arctic char in marine and freshwaters: the effects of salmon farms. Aquac Res 32:947-962

Budgell WP (2005) Numerical simulation of ice-ocean variability in the Barents Sea region. Ocean Dyn 55:370-387. https://doi.org/10. 1007/s10236-005-0008-3

Chapman DC (1985) Numerical treatment of cross-shelf open boundaries in a barotropic coastal ocean model. J Phys Oceanogr 15(8):1060 1075. https://doi.org/10.1175/1520-0485(1985)015

Dee DP (1995) On-line estimation of error covariance parameters for atmospheric data assimilation. Mon Weather Rev 123(4):1128-1145

Egbert GD, Erofeeva SY (2002) Efficient inverse modeling of barotropic ocean tides. J Atmos Ocean Technol 19(2):183-204. https://doi.org/ 10.1175/1520-0426(2002)019

Farmer DM, Freeland HJ (1983) The physical oceanography of fjords. Prog Oceanogr 12:147-220

Finstad B, Bjorn PA, Grimnes A, Hvidsten NA (2000) Laboratory and field investigations of salmon lice [Lepeophtheirus salmonis (Kroyer)] infestation on Atlantic salmon (Salmo salar L.) postsmolts. Aquac Res 31:795-803

Flather R (1976) A tidal model of the northwest European continental shelf. Mem Soc R Sci Liege 10:141-164

Gade HG, Edwards A (1980) Deep water renewal in fjords. In: Freeland HJ, Farmer DM, Levings CD (eds) Fjord oceanography. NATO conference series. Plenum Press, NewYork, pp 453-489

Gjevik B, Straume T (1989) Model simulations of the $\mathrm{M}_{2}$ and the $\mathrm{K}_{1}$ tide in the Nordic seas and the Arctic Ocean. Tellus 41A:73-96

Haidvogel D, Arango H, Budgell W, Cornuelle B, Curchitser E, Lorenzo ED, Fennel K, Geyer W, Hermann A, Lanerolle L, Levin J, McWilliams J, Miller A, Moore A, Powell T, Shchepetkin A, Sherwood C, Signell R, Warner J, Wilkin J (2008) Ocean forecasting in terrain-following coordinates: Formulation and skill assessment of the Regional Ocean Modeling System. J Comput Phys 227(7): 3595-3624, predicting weather, climate and extreme events. https:// doi.org/10.1016/j.jcp.2007.06.016

Hamre LA, Eichner C, Caipang CMA, Dalvin ST, Bron JE, Nilsen F, Boxshall G, Skern-Mauritzen R (2013) The salmon louse Lepeophtheirus salmonis (Copepoda: Caligidae) life cycle has only two chalimus stages. PLoS One 8:e73539

Heuch PA, Mo TA (2001) A model of salmon louse production in Norway: effects of increasing salmon production and public management measures. Dis Aquat Org 45:145-152

Heuch PA, Bjorn PA, Finstad B, Asplin L, Holst JC (2009) Salmon lice infection of farmed and wild salmonids in Norway: an overview. Integr Comp Biol 49:E74

Heuch PA, Gettinby G, Revie CW (2011) Counting sea lice on Atlantic salmon farms - empirical and theoretical observations. Aquaculture 320:149-153

Inall ME, Gillibrand PA (2010) The physics of mid-latitude fjords: a review. Geol Soc Lond Spec Publ 344:17-33. https://doi.org/10. 1144/SP344.3

Johnsen IA, Fiksen Ø, Sandvik AD, Asplin L (2014) Vertical salmon lice behaviour as a response to environmental conditions and its influence on regional dispersion in a fjord system. Aquacult Environ Interact 5:127-141. https://oi.org/10.3354/aei00098

Johnsen IA, Asplin L, Sandvik AD, Serra-Llinares RM (2016) Salmon lice dispersion in a northern Norwegian fjord system and the impact of vertical movements. Aquacult Environ Interact 8:99-116. https:// doi.org/10.3354/aei00162

Johnson SC, Albright LJ (1991) The developmental stages of Lepeophtheirus salmonis (Krøyer, 1837) (Copepoda: Caligidae). Can J Zool 69:929-950 
Lien VS, Gusdal Y, Vikebø FB (2014) Along-shelf hydrographic anomalies in the Nordic seas (1960-2011): locally generated or advective signals? Ocean Dyn 64(7):1047-1059

Marchesiello P, McWilliams JC, Shchepetkin A (2001) Open boundary conditions for long-term integration of regional oceanic models. Ocean Model 3(1):1-20. https://doi.org/10.1016/S1463-5003(00)00013-5

Ministry of Trade, Industry and Fisheries (2015) Forutsigbar og miljømessig bærekraftig vekst i norsk lakse- og ørretoppdrett. Meld. St. 16 (2014-2015), Ministry of Trade, Industry and Fisheries, Oslo

Myksvoll MS, Sandvik AD, Albretsen J, Asplin L, Johnsen IA, Karlsen Ø, Kristensen NM, Melsom A, Skarðhamar J, Ådlandsvik B (2018) Evaluation of a national operational salmon lice monitoring system - from physics to fish. PLoS One 13(7):e0201338

Oppedal F, Dempster T, Stien LH (2011) Environmental drivers of Atlantic salmon behaviour in sea-cages: a review. Aquaculture 311:1-18. https://doi.org/10.1016/j.aquaculture.2010.11.020

Parding KM, Benestad R, Mezghani A, Erlandsen HB (2019) Statistical projection of the North Atlantic storm tracks. J Appl Meteorol Climatol 58(7):1509-1522

Pike AW, Wadsworth SL (1999) Sealice on salmonids: their biology and control. Adv Parasitol 44:233-337

Sætre R (ed) (2007) The Norwegian coastal current —oceanography and climate. Tapir Academi c Press, Trondheim, p 159

Samsing F, Johnsen I, Treml EA, Dempster T (2018) Identifying 'firebreaks' to fragment dispersal networks of a marine parasite. Int J Parasitol. https://doi.org/10.1016/j.ijpara.2018.11.00

Sandvik AD, Bjørn PA, Ådlandsvik B, Asplin L, Skarðhamar J, Johnsen IA, Myksvoll M, Skogen MD (2016a) Toward a model-based prediction system for salmon lice infestation pressure. Aquacult Environ Interact 8:527-542. https://doi.org/10.3354/aei00193

Sandvik AD, Skagseth Ø, Skogen MD (2016b) Model validation: issues regarding comparisons of point measurements and high-resolution modeling results. Ocean Model 106:68-73. https://doi.org/10.1016/ j.ocemod.2016.09.007

Sandvik AD, Johnsen IA, Myksvoll M, Sævik PN, Skogen MD (2020) Prediction of the salmon lice infestation pressure in a Norwegian fjord Accepted for publication in. ICES J Mar Sci 77:746-756. https://doi.org/10.1093/icesjms/fsz256
Serra-Llinares RM, Bjørn PA, Finstad B, Nilsen R, Harbitz A, Berg M, Asplin L (2014) Salmon lice infection on wild salmonids in marine protected areas: an evaluation of the Norwegian 'National Salmon Fjords'. Aquacult Environ Interact 5:1-16. https://doi.org/10.3354/ aei00090

Serra-Llinares RM, Freitas C, Nilsen R, Elvik KMS, Albretsen J, Bøhn T, Karlsen Ø, Bjørn PA (2018) Towards direct evidence of the effects of salmon lice (Lepeophtheirus salmonis Krøyer) on sea trout (Salmo trutta L.) in their natural habitat: proof of concept for a new combination of methods. Environ Biol Fish 101:1677-1692

Shchepetkin AF, McWilliams JC (2005) The regional oceanic modeling system (ROMS): a split-explicit, free-surface, topographyfollowing- coordinate oceanic model. Ocean Model 9(4):347-404. https://doi.org/10.1016/j.ocemod.2004.08.002

Skamarock W, Klemp J, Dudhia J, Gill D, Barker D, Duda M, Huang XY, Wang W (2008) A description of the advanced research WRF version 3, NCAR technical note NCAR/TN-475+STR, p. 113

Skarðhamar J, Albretsen J, Sandvik AD, Lien VS, Myksvoll MS, Johnsen IA, Asplin L, Ådlandsvik B, Halttunen E, Bjørn PA (2018) Modelled salmon lice dispersion and infestation patterns in a sub-arctic fjord. ICES J Mar Sci:1-15. https://doi.org/10.1093/ icesjms/fsy035

Stien A, Bjørn PA, Heuch PA, Elston DA (2005) Population dynamics of salmon lice Lepeophtheirus salmonis on Atlantic salmon and sea trout. Mar Ecol Prog Ser 290:263-275

Stigebrandt A (2012) Hydrodynamics and circulation of fjords. In: Bengtsson L, Herschy RW, Fairbridge RW (eds) Encyclopedia of lakes and reservoirs. Springer, Berlin, pp 327-344

Taranger GL, Karlsen Ø, Bannister RJ, Glover KA, Husa V, Karlsbakk E, Kvamme BO, Boxaspen KK, Bjørn PA, Finstad B, Madhun AS, Morton HC, Svåsand T (2015) Risk assessment of the environmental impact of Norwegian Atlantic salmon farming. ICES J Mar Sci 72:997-1021

Umlauf LH, Burchard (2003) A generic length-scale equation for geophysical turbulence models. J Mar Res 61:235-265

Ziegler S, Dykes J, Shriver J (2012) Spatial error metrics for oceanographic model verification. J Atmos Ocean Technol 29:260-266 